\title{
Effect of synthetic route on sintering behaviour, phase purity and conductivity of Sr- and $\mathrm{Mg}$-doped $\mathrm{LaGaO}_{3}$ perovskites
}

\author{
Riccardo Polini*, Arianna Pamio, Enrico Traversa \\ Dipartimento di Scienze e Tecnologie Chimiche, Università di Roma Tor Vergata, Via della Ricerca Scientifica, 00133 Rome, Italy
}

\begin{abstract}
$\mathrm{La}_{1-x} \mathrm{Sr}_{x} \mathrm{Ga}_{1-y} \mathrm{Mg}_{y} \mathrm{O}_{3-\delta}$ (LSGM) powders containing different amounts of $\mathrm{Sr}^{2+}$ and $\mathrm{Mg}^{2+}$ were prepared from precursors synthesised by either Pechini or citrate sol-gel method and by subsequent calcination at $1400{ }^{\circ} \mathrm{C}$. Some powders were also submitted to further $10 \mathrm{~h}$ firing at $1500{ }^{\circ} \mathrm{C}$. All as-calcined powders contained small amounts of Sr- and Ga-containing phases (namely $\mathrm{SrLaGa}_{3} \mathrm{O}_{7}$ and $\mathrm{SrLaGaO}_{4}$ ), as detected by X-Ray Diffraction (XRD). The relative amounts of these phases depended on $x$ and $y$, i.e. the dopants' levels. Nevertheless, powders prepared by the citrate method exhibited systematically higher phase purity than those obtained by the Pechini process. Calcined powders were then sintered at $1500{ }^{\circ} \mathrm{C}(10 \mathrm{~h})$ in air and the degree of sintering was assessed by scanning electron microscopy (SEM). Phase composition of sintered pellets was different from that of powders. In fact, sintered pellets showed the presence of $\mathrm{MgO}$, as detected by SEM, and of lesser amounts of $\mathrm{SrLaGa}_{3} \mathrm{O}_{7}$. Both these phases were less abundant in materials sintered using powders prepared by citrate method, thus suggesting that Pechini method does not represent the best wet chemical process for manufacturing. The conductivity of sintered pellets was measured by impedance spectroscopy in the $600-800{ }^{\circ} \mathrm{C}$ interval. Conductivity values of LSGM materials were affected by secondary phase segregation and, therefore, depended on both composition and sol-gel method synthetic route.
\end{abstract}

(C) 2003 Elsevier Ltd. All rights reserved.

Keywords: Fuel cells; Perovskites; Powders-chemical preparation; Sintering; Electrical conductivity

\section{Introduction}

Strontium- and/or magnesium-doped lanthanum gallate $\left(\mathrm{LaGaO}_{3}\right)$ ceramics are known to have superior oxygen ion conducting properties over a broad range of oxygen partial pressures.

The ionic conductivity of $\mathrm{La}_{1-x} \mathrm{Sr}_{x} \mathrm{Ga}_{1-y} \mathrm{Mg}_{y} \mathrm{O}_{3-\delta}$ (LSGM, where $\delta=(x+y) / 2$ ) materials at $700{ }^{\circ} \mathrm{C}$ is about 4 times larger than that of yttria-stabilized zirconia (YSZ), ${ }^{1-3}$ thus promising to replace YSZ for use in reduced-temperature solid-oxide fuel cells (SOFCs). ${ }^{1,4}$ Moreover, according to Ishihara et al., ${ }^{1}$ the electromotive force (emf) of $\mathrm{H}_{2}-\mathrm{H}_{2} \mathrm{O} / \mathrm{LSGM} /$ air cells is close to the theoretical value, with evident advantages with respect to other reduced-temperature SOFCs using solid electrolytes based on $\mathrm{CeO}_{2}$ or $\mathrm{Bi}_{2} \mathrm{O}_{3}$.

LSGM materials can be prepared by conventional solid state reactive firing, ${ }^{1,2}$ ultrasonic spray pyrolysis ${ }^{5}$ or by combustion synthesis. ${ }^{6}$ Huang et al. have used wet

\footnotetext{
* Corresponding author. Tel.: + 39-06-7259-4414; fax: +39-7259-

E-mail address: polini@uniroma2.it (R. Polini).
} 4328 . chemical syntheses, namely a coprecipitation route with $\mathrm{NH}_{4} \mathrm{OH}$ from lanthanum, strontium, magnesium and gallium water soluble salts ${ }^{3}$ and a sol-gel method. ${ }^{7}$ Tas et al. ${ }^{8}$ have studied the preparation of LSGM powders by Pechini method, ${ }^{9}$ which is a versatile sol-gel method that proceeds via the formation of a polymeric resin using citric acid and ethylene glycol.

However, both phase purity and microstructure of LSGM materials depend on synthetic procedure and processing and, as a matter of fact, the synthesis of a pure single phase material is rather difficult. ${ }^{5}$ Even solgel methods, which ensure the formation of polymeric precursor resins where cations are expected to be uniformly dispersed at an atomic scale, can give rise to LSGM materials containing, at the end of the preparation process, small amounts of undesired phases such as $\mathrm{LaSrGa}_{3} \mathrm{O}_{7}$ and $\mathrm{LaSrGaO}_{4}{ }^{8}$

Majewski et al. ${ }^{9}$ showed that sintering temperatures higher than $1400{ }^{\circ} \mathrm{C}$ were necessary to prepare pure $\mathrm{La}_{0.8} \mathrm{Sr}_{0.2} \mathrm{Ga}_{0.8} \mathrm{Mg}_{0.2} \mathrm{O}_{2.8}$ ceramics by mixed oxide route.

In this work, Sr- and $\mathrm{Mg}$-doped $\mathrm{LaGaO}_{3}$ materials were prepared using two different sol-gel methods, namely by Pechini method ${ }^{10}$ or from citrate 
precursors. ${ }^{11}$ The materials were characterized in terms of phase purity of powders and pellets sintered at $1500{ }^{\circ} \mathrm{C}$ in air, as well as electrical conductivity of pellets in the $600-800{ }^{\circ} \mathrm{C}$ temperature range.

\section{Experimental}

The powders were synthesized using the following starting materials, supplied by Sigma-Aldrich S.r.l., Milan, Italy: $\mathrm{La}\left(\mathrm{NO}_{3}\right)_{3} \cdot x \mathrm{H}_{2} \mathrm{O}(99.9 \%$ pure $), \mathrm{Ga}\left(\mathrm{NO}_{3}\right)_{3} \cdot y \mathrm{H}_{2} \mathrm{O}$ $(99.999 \%$ pure $), \quad \mathrm{Sr}\left(\mathrm{NO}_{3}\right)_{2} \quad(99.995 \%$ pure $)$, and $\mathrm{Mg}\left(\mathrm{NO}_{3}\right)_{2} \cdot 6 \mathrm{H}_{2} \mathrm{O}(99.995 \%$ pure). The values of $x$ and $y$ in the above formulas of lanthanum nitrate and gallium nitrate were determined experimentally to be 5.0 and 9.3, respectively, by using thermogravimetric analysis (TGA, Netzsch STA 409).

Stoichiometric amounts of nitrates that corresponded to $2.5 \mathrm{~g}$ of lanthanum gallate resins (pure or Sr- and Mg-doped) were dissolved in deionised water. Then, a mixture of 60 wt. \% citric acid monohydrate $(99 \%$ pure, Sigma-Aldrich) and $40 \mathrm{wt} . \%$ ethylene glycol (99\% pure, Carlo Erba, Italy) was added to the water solution, being 1:1.88 the molar ratio of citric acid to total cations. The resulting solution was stirred for $1 \mathrm{~h}$ at room temperature and then evaporated for $3 \mathrm{~h}$ until a resin formed. The obtained resins (after overnight drying in an oven at $110{ }^{\circ} \mathrm{C}$ ) were calcined isothermally in the temperature range $800-1500{ }^{\circ} \mathrm{C}\left(5^{\circ} \mathrm{C} / \mathrm{min}\right.$ heating rate). The upper limit of the calcination temperature range $\left(1500{ }^{\circ} \mathrm{C}\right)$ was selected according to the results by Majewski et al. ${ }^{12}$ and by Huang et al., ${ }^{15}$ which indicated that solid solubility of $\mathrm{Sr}$ and $\mathrm{Mg}$ in $\mathrm{LaGaO}_{3}$ tends to increase with temperature.

The same starting materials used for the Pechini method were used for citrate synthesis. Stoichiometric amounts of nitrates that corresponded to $2.5 \mathrm{~g}$ of lanthanum gallate resins (pure or $\mathrm{Sr}-$ and $\mathrm{Mg}$-doped) were dissolved in deionised water. Then, pure citric acid monohydrate was added to the water solution, being 1:2 the molar ratio of citric acid to total cations. Therefore, the main difference with respect to Pechinitype process was the absence of ethylene glycol. The resulting solution was stirred for $1 \mathrm{~h}$ and then evaporated for $3 \mathrm{~h}$ until a resin formed. The obtained resins (after overnight drying in an oven at $110^{\circ} \mathrm{C}$ ) were calcined isothermally in air at 1400 or $1500{ }^{\circ} \mathrm{C}\left(5^{\circ} \mathrm{C} / \mathrm{min}\right.$ heating rate).

Table 1 summarizes the ceramic powders obtained by both sol-gel methods. LG refers to pure lanthanum gallate; $\mathrm{LS}_{x} \mathrm{GM}_{y}$ labels refer to doped $\mathrm{La}_{1-x} \mathrm{Sr}_{x} \mathrm{Ga}_{1-y}$ $\mathrm{Mg}_{y} \mathrm{O}_{3-\delta}$ materials.

Pellets $(13 \mathrm{~mm}$ diameter $)$ of $\mathrm{LS}_{0.1} \mathrm{GM}_{0.1}$ powders synthesised by either Pechini (LSGM/P) or citrate (LSGM/C) method and of $\mathrm{LS}_{0.1} \mathrm{GM}_{0.1}$ powder obtained by citrate method were uniaxially pressed using
Table 1

Lanthanum gallate $\left(\mathrm{LaGaO}_{3}, \quad \mathrm{LG}\right)$ and $\mathrm{La}_{1-x} \mathrm{Sr}_{x} \mathrm{Ga}_{1-y} \mathrm{Mg}_{y} \mathrm{O}_{3-\delta}$ $\left(\mathrm{LS}_{x} \mathrm{GM}_{y}\right)$ powders prepared by Pechini $(P)$ or citrate $(C)$ sol-gel synthesis

\begin{tabular}{lll}
\hline & Powder & Calcination treatment \\
\hline Pechini & $\mathrm{LG} / \mathrm{P}$ & $6 \mathrm{~h}$ in the $800-1200{ }^{\circ} \mathrm{C}$ T range \\
& $\mathrm{LS}_{0.2} \mathrm{GM}_{0.15} / \mathrm{P}$ & $9 \mathrm{~h}$ in the $900-1400{ }^{\circ} \mathrm{C}$ T range \\
& $\mathrm{LS}_{0.15} \mathrm{GM}_{0.15} / \mathrm{P}$ & $1400{ }^{\circ} \mathrm{C}, 9 \mathrm{~h}$ \\
& $\mathrm{LS}_{0.1} \mathrm{GM}_{0.15} / \mathrm{P}$ & $1400{ }^{\circ} \mathrm{C}, 9 \mathrm{~h}$ \\
& $\mathrm{LS}_{0.1} \mathrm{GM}_{0.1} / \mathrm{P}$ & $1400{ }^{\circ} \mathrm{C}, 15 \mathrm{~h}+1500{ }^{\circ} \mathrm{C}, 10 \mathrm{~h}$ \\
& $\mathrm{LS}_{0.1} \mathrm{GM}_{0.1} / \mathrm{P}$ & $1400{ }^{\circ} \mathrm{C}, 9 \mathrm{~h}$ \\
& & \\
Citrate & $\mathrm{LS}_{0.1} \mathrm{GM}_{0.1} / \mathrm{C}$ & $1400{ }^{\circ} \mathrm{C}, 15 \mathrm{~h}+1500{ }^{\circ} \mathrm{C}, 10 \mathrm{~h}$ \\
& $\mathrm{LS}_{0.1} \mathrm{GM}_{0.1} / \mathrm{C}$ & $1400{ }^{\circ} \mathrm{C}, 9 \mathrm{~h}$ \\
& $\mathrm{LS}_{0.1} \mathrm{GM}_{0.2} / \mathrm{C}$ & $1400{ }^{\circ} \mathrm{C}, 9 \mathrm{~h}$ \\
& $\mathrm{LS}_{0.15} \mathrm{GM}_{0.2} / \mathrm{C}$ & $1400{ }^{\circ} \mathrm{C}, 9 \mathrm{~h}$ \\
& $\mathrm{LS}_{0.2} \mathrm{GM}_{0.15} / \mathrm{C}$ & $1400{ }^{\circ} \mathrm{C}, 9 \mathrm{~h}$ \\
\hline
\end{tabular}

compaction pressures in the range 150-600 $\mathrm{MPa}$ and sintered in air at $1500{ }^{\circ} \mathrm{C}(10 \mathrm{~h})$.

The phases present in both calcined powders and sintered pellets were analysed using X-Ray Diffraction (XRD). Scans were taken with a $2 \theta$ step of $0.02^{\circ}$ and using graphite-filtered $\mathrm{CuK} \alpha$ radiation $(40 \mathrm{kV}, 40 \mathrm{~mA})$. Lattice parameters were evaluated from reflections appearing in the range $2 \theta=10-90^{\circ}$, by means of the UNIT-CELL program.

Morphology of the powders and microstructure of sintered pellets were assessed by scanning electron microscopy (SEM) and Energy Dispersive X-Ray Spectroscopy (EDS).

Electrical conductivity measurements of the pellets were made in air by using porous Pt-electrodes (Pt-paste onto the flat surface and cured at $800{ }^{\circ} \mathrm{C}$ for $10 \mathrm{~min}$ ) in the $600-800{ }^{\circ} \mathrm{C}$ temperature interval by employing a Solatron mod. 126 impedance analyzer $\left(10-10^{-3} \mathrm{MHz}\right)$. The intercept of the semicircle with the real axis was taken for the calculation of the electrical conductivity data.

\section{Results and discussion}

Fig. 1 shows the XRD spectra of $\mathrm{LS}_{0.2} \mathrm{GM}_{0.15}$ powders prepared by Pechini method and calcined for $9 \mathrm{~h}$ at different temperatures. After calcination at $900{ }^{\circ} \mathrm{C}$, only low intensity perovskite peaks could be detected in the XRD spectrum and the precursor powder consisted of a mixture of a number of phases. Even after $9 \mathrm{~h}$ calcination at $1400{ }^{\circ} \mathrm{C}$, the precursor powder was not singlephase. In fact, the most intense diffraction peaks of $\mathrm{SrLaGaO}_{4}$ and $\mathrm{SrLaGa}_{3} \mathrm{O}_{7}$ were still detectable in the XRD pattern. The relative amounts of these two secondary phases decreased with the increase of calcination temperature and it was decided to heat all LSGM precursor powders at temperatures not lower than $1400^{\circ} \mathrm{C}$. 
It is worth noting that pure $\mathrm{LaGaO}_{3}$ phase could be obtained by $6 \mathrm{~h}$ calcination at $900{ }^{\circ} \mathrm{C}$ of the LG powder precursors synthesised by Pechini method. Fig. 2 shows the full width at half maximum (FWHM) of the (121) peak of $\mathrm{LG}$ and $\mathrm{LS}_{0.2} \mathrm{GM}_{0.15}$ perovskites as a function of the calcination temperature. For each phase, the data indicated a reduction of FWHM with the increase of calcination temperature, thus suggesting an increase of the average grain size. However, XRD peaks of $\mathrm{LS}_{0.2} \mathrm{GM}_{0.15}$ phase were systematically larger than diffraction peaks of LG phase calcined at the same temperature and for a shorter time. Fig. 3 shows that the average particle size of $L G$ and $\mathrm{LS}_{0.2} \mathrm{GM}_{0.15}$ powders after calcination at $1200{ }^{\circ} \mathrm{C}$ was comparable. Quite similar results were observed also at the other calcination temperatures. Therefore, the broader XRD peaks of $\mathrm{LS}_{0.2} \mathrm{GM}_{0.15}$ powder calcined at a given temperature

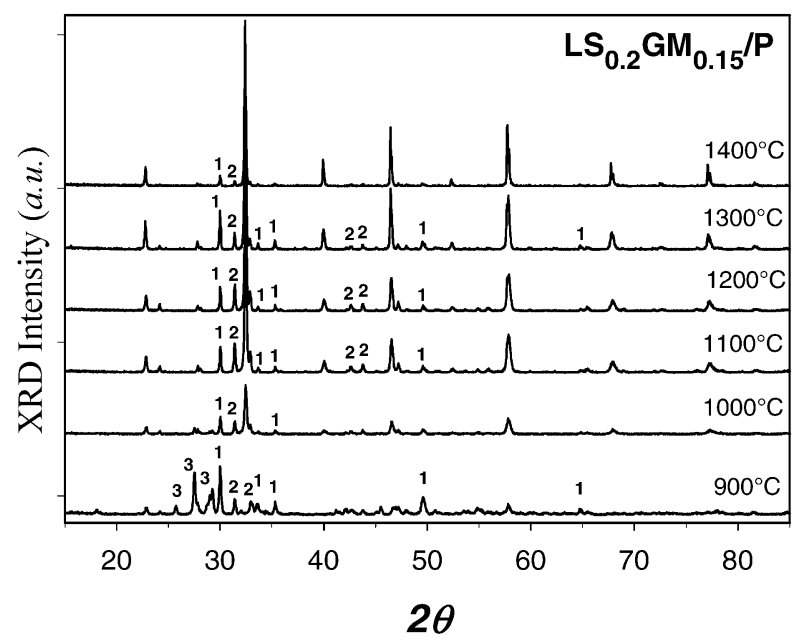

Fig. 1. XRD spectra of $\mathrm{LS}_{0.2} \mathrm{GM}_{0.15}$ precursor powders calcined at different temperatures. (1) $\mathrm{SrLaGa}_{3} \mathrm{O}_{7}$; (2) SrLaGaO4; (3) $\mathrm{La}_{2} \mathrm{O}_{3}$ and $\mathrm{LaOOH}$. All other reflections are attributed to LSGM phase.

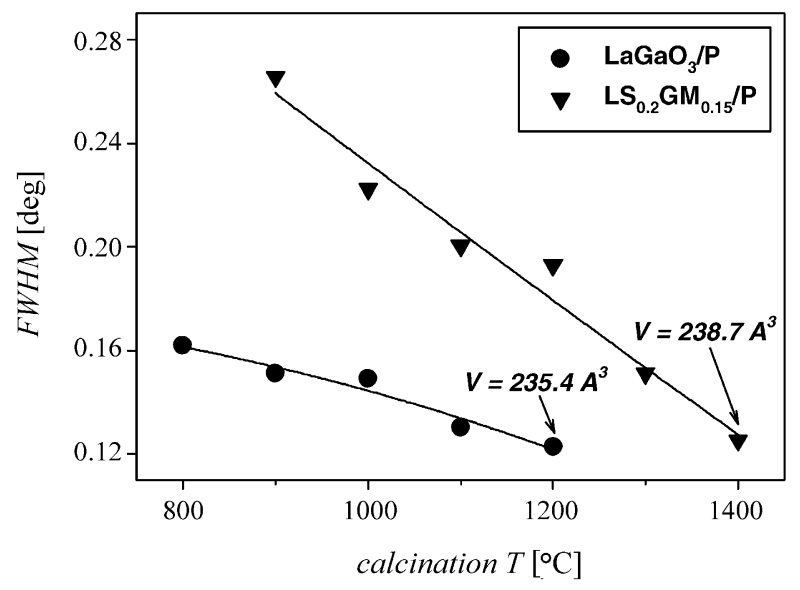

Fig. 2. FWHM of the (121) XRD peak of $\mathrm{LaGaO}_{3}$ (circles) and $\mathrm{LS}_{0.2} \mathrm{GM}_{0.15}$ (triangles) perovskite phases as a function of calcination temperature. LG and LSGM calcination times were 6 and $9 \mathrm{~h}$, respectively. cannot be attributed to crystallite size effects, but mostly to the presence of vacancies in the doped phase, which reduce the long range order of the perovskite phase. The unit cell volumes of $\mathrm{LG}$ and $\mathrm{LS}_{0.2} \mathrm{GM}_{0.15}$ phases calcined at the highest temperatures were 235.4 and 238.7 $\AA^{3}$. The larger volume of the $\mathrm{Sr}$ - and $\mathrm{Mg}$-doped phase with respect to pure orthorhombic lanthanum gallate is a further consequence of the presence of oxygen vacancies concentration and consequent lattice relaxation. Similar results were obtained by Tas et al. ${ }^{8}$ for $\mathrm{Sr}$-doped $\mathrm{LaGaO}_{3}$ prepared by using a Pechini-type process. In fact, they found that the unit cell volume of $\mathrm{La}_{0.9} \mathrm{Sr}_{0.1^{-}}$ $\mathrm{GaO}_{2.95}$ perovskite was $0.28 \%$ larger than pure $\mathrm{LaGaO}_{3}$ synthesized by using the same process. ${ }^{8}$

To study the role of dopant levels and of the synthetic route on the presence of secondary phases in powders calcined at $1400{ }^{\circ} \mathrm{C}$, the relative amounts of $\mathrm{SrLaGaO}_{4}$ and $\mathrm{SrLaGa}_{3} \mathrm{O}_{7}$ were estimated by measuring the ratio, $A_{s} / A_{p}$, of the total integrated intensities of the most intense XRD peaks of these phases over the integrated intensity of the (121) peak of the perovskite. In Table 2 the $A_{s} / A_{p}$ ratios for $\mathrm{LS}_{x} \mathrm{GM}_{y}$ calcined powders, whose
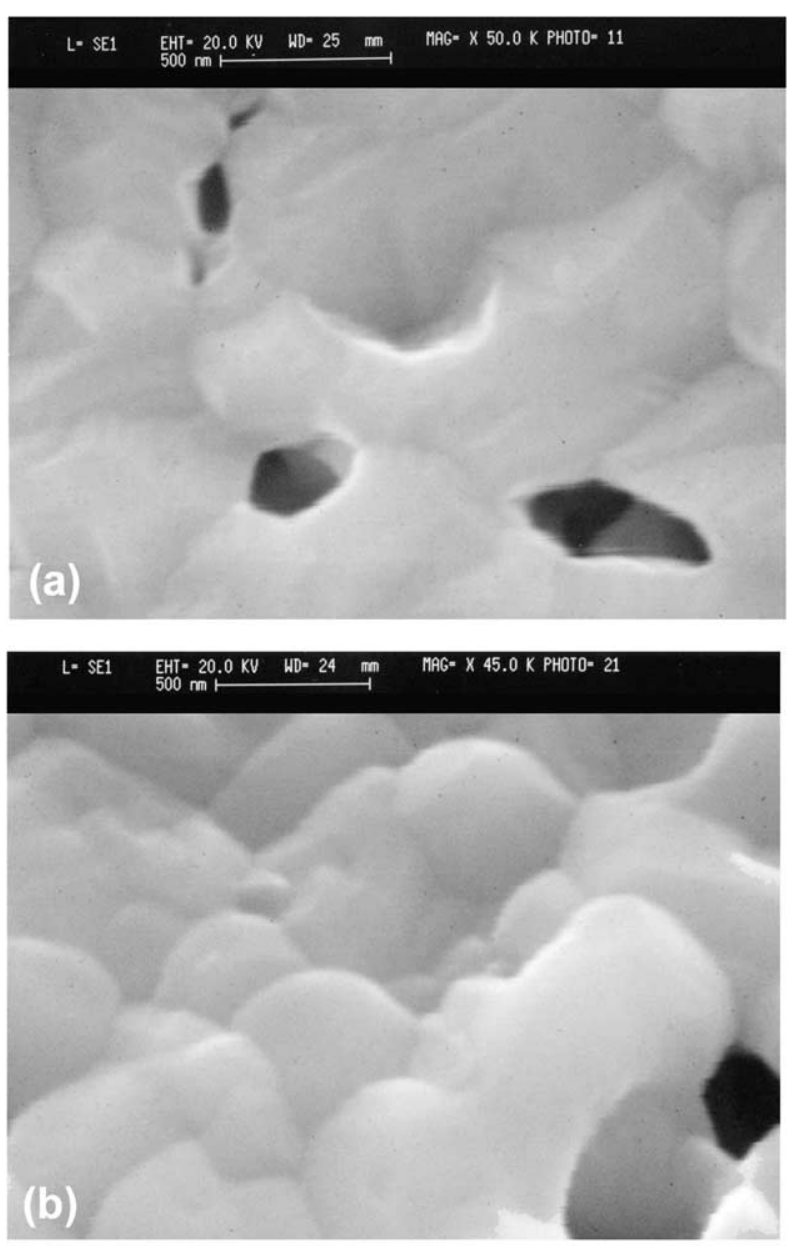

Fig. 3. SEM micrographs of $\mathrm{LaGaO}_{3}$ (a) and $\mathrm{LS}_{0.2} \mathrm{GM}_{0.15}$ (b) powders calcined at $1200{ }^{\circ} \mathrm{C}$ for 6 and $9 \mathrm{~h}$, respectively. 
precursors were synthesised by Pechini (LSGM/P) or citrate $(\mathrm{LSGM} / \mathrm{C})$ method, are reported. The data showed that: (1) at a given $\mathrm{Sr}$ content, the relative amounts of $\mathrm{SrLaGaO}_{4}$ and $\mathrm{SrLaGa}_{3} \mathrm{O}_{7}$ decreased with the increase of $\mathrm{Mg}$, i.e. with the decrease of gallium content in the doped perovskite; (2) at a given $\mathrm{Mg}$ content, the amount of Sr-containing secondary phases increased with $x$, i.e. with the strontium content; (3) the performance of a longer calcination run at $1400{ }^{\circ} \mathrm{C}$ followed by a further $10 \mathrm{~h}$ calcination at $1500{ }^{\circ} \mathrm{C} \mathrm{did}$ not allow us to significantly reduce the amount of $\mathrm{SrLaGa}_{3} \mathrm{O}_{7}$ in the powder; (4) the citrate method did allow us to obtain LSGM materials with a slightly larger phase purity.

Table 2

Ratio $\left(A_{s} / A_{p}\right)$ of the total integrated intensities of the most intense XRD peaks of secondary phases over the integrated intensity of the (121) peak of perovskite. The $A_{s} / A_{p}$ values represent a semi quantitative estimation of the percentage of secondary phases as a function of Sr- and Mg-content in calcined LSGM materials prepared by Pechini $(\mathrm{LSGM} / \mathrm{P})$ or citrate $(\mathrm{LSGM} / \mathrm{C})$ method $^{\mathrm{a}}$

\begin{tabular}{llll}
\hline Powder & Heat treatment & XRD phases & $A_{\mathrm{s}} / A_{\mathrm{p}} \times 100$ \\
\hline $\mathrm{LS}_{0.2} \mathrm{GM}_{0.15} / \mathrm{P}$ & $1400^{\circ} \mathrm{C}(9 \mathrm{~h})$ & $\mathrm{P}+1+2$ & 7.4 \\
$\mathrm{LS}_{0.15} \mathrm{GM}_{0.15} / \mathrm{P}$ & $1400^{\circ} \mathrm{C}(9 \mathrm{~h})$ & $\mathrm{P}+1$ & 9.6 \\
$\mathrm{LS}_{0.1} \mathrm{GM}_{0.1} / \mathrm{P}$ & $1400^{\circ} \mathrm{C}(9 \mathrm{~h})$ & $\mathrm{P}+1$ & 8.8 \\
$\mathrm{LS}_{0.1} \mathrm{GM}_{0.1} / \mathrm{P}$ & $1400{ }^{\circ} \mathrm{C}(15 \mathrm{~h})$ & $P+1$ & 7.7 \\
& $+1500^{\circ} \mathrm{C}(10 \mathrm{~h})$ & & \\
$\mathrm{LS}_{0.1} \mathrm{GM}_{0.15} / \mathrm{P}$ & $1400{ }^{\circ} \mathrm{C}(9 \mathrm{~h})$ & $P+1$ & 5.6 \\
$\mathrm{LS}_{0.1} \mathrm{GM}_{0.2} / \mathrm{P}$ & $1400^{\circ} \mathrm{C}(9 \mathrm{~h})$ & $P+1$ & 3.0 \\
$\mathrm{LS}_{0.1} \mathrm{GM}_{0.1} / \mathrm{C}$ & $1400^{\circ} \mathrm{C}(9 \mathrm{~h})$ & $P+1$ & 6.0 \\
$\mathrm{LS}_{0.1} \mathrm{GM}_{0.1} / \mathrm{C}$ & $1400^{\circ} \mathrm{C}(15 \mathrm{~h})$ & $P+1$ & 6.2 \\
$\mathrm{LS}_{0.1} \mathrm{GM}_{0.2} / \mathrm{C}$ & $1400{ }^{\circ} \mathrm{C}(9 \mathrm{~h})$ & $P+1$ & 1.5 \\
$\mathrm{LS}_{0.1} \mathrm{GM}_{0.2} / \mathrm{C}$ & $1400^{\circ} \mathrm{C}(9 \mathrm{~h})$ & $P+1$ & 2.0 \\
$\mathrm{LS}_{0.15} \mathrm{GM}_{0.2} / \mathrm{C}$ & $1400^{\circ} \mathrm{C}(9 \mathrm{~h})$ & $P+1$ & 4.9
\end{tabular}

a phases: $\mathrm{P}=$ perovskite; $1=\mathrm{SrLaGa}_{3} \mathrm{O}_{7} ; 2=\mathrm{SrLaGaO}_{4}$.

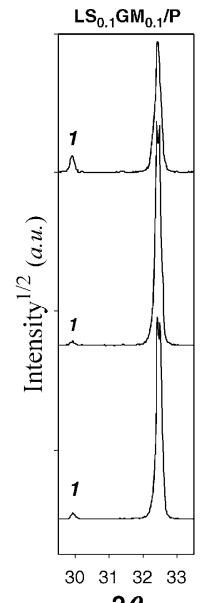

$2 \theta$

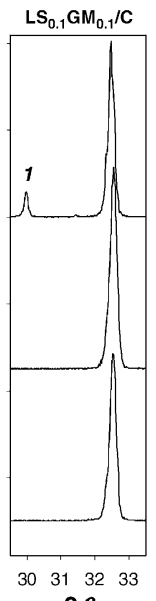

$2 \theta$

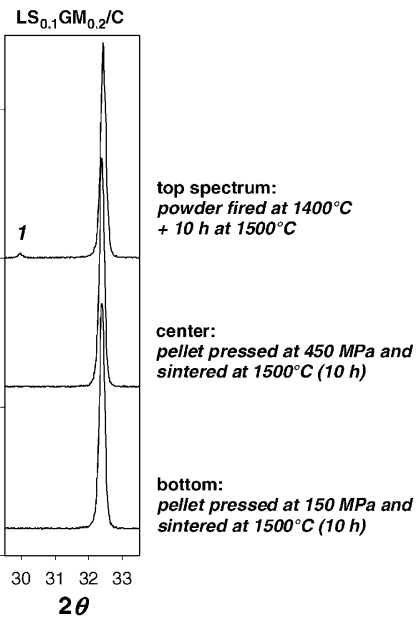

$2 \theta$
Fig. 4. XRD spectra of LSGM sintered pellets and powders submitted to same heat treatment $\left(1: \mathrm{SrLaGa}_{3} \mathrm{O}_{7}\right.$ phase, the other reflection is the (121) peak of perovskite).
XRD spectra of sintered pellets showed that the relative amounts of $\mathrm{Sr}$-containing secondary phases decreased after sintering. Fig. 4 shows XRD peaks in the range $2 \theta=29.5-33.5^{\circ}$ for $\mathrm{LS}_{0.1} \mathrm{GM}_{0.1} / \mathrm{P}, \mathrm{LS}_{0.1} \mathrm{GM}_{0.1} /$ $\mathrm{C}$ and $\mathrm{LS}_{0.1} \mathrm{GM}_{0.2} / \mathrm{C}$ sintered pellets and powders submitted to same heat treatment. The data clearly showed that the relative amount of $\mathrm{SrLaGa}_{3} \mathrm{O}_{7}$ (peak 1 in Fig. 4) in sintered pellets was undetectable (in the case of LSGM/C pellets prepared by citrate method) or much less than in the powders (in the case of LSGM/P pellets), even if the powders underwent the same thermal treatment (calcination at $1400{ }^{\circ} \mathrm{C}$ followed by a further $10 \mathrm{~h}$ at $1500{ }^{\circ} \mathrm{C}$ ). Moreover, the solid state reaction that led to decomposition of $\mathrm{SrLaGa}_{3} \mathrm{O}_{7}$ was not significantly affected by the compaction pressures here employed, being identical the XRD spectra of sintered pellets pressed at 150 or $450 \mathrm{MPa}$.

Sintered pellets, which were uniaxially pressed at pressures larger than $150 \mathrm{MPa}$, were dense, as evidenced by SEM. Fig. 5 shows the SEM micrographs of $\mathrm{LS}_{0.1} \mathrm{GM}_{0.1}$ pellets prepared from powders pressed at
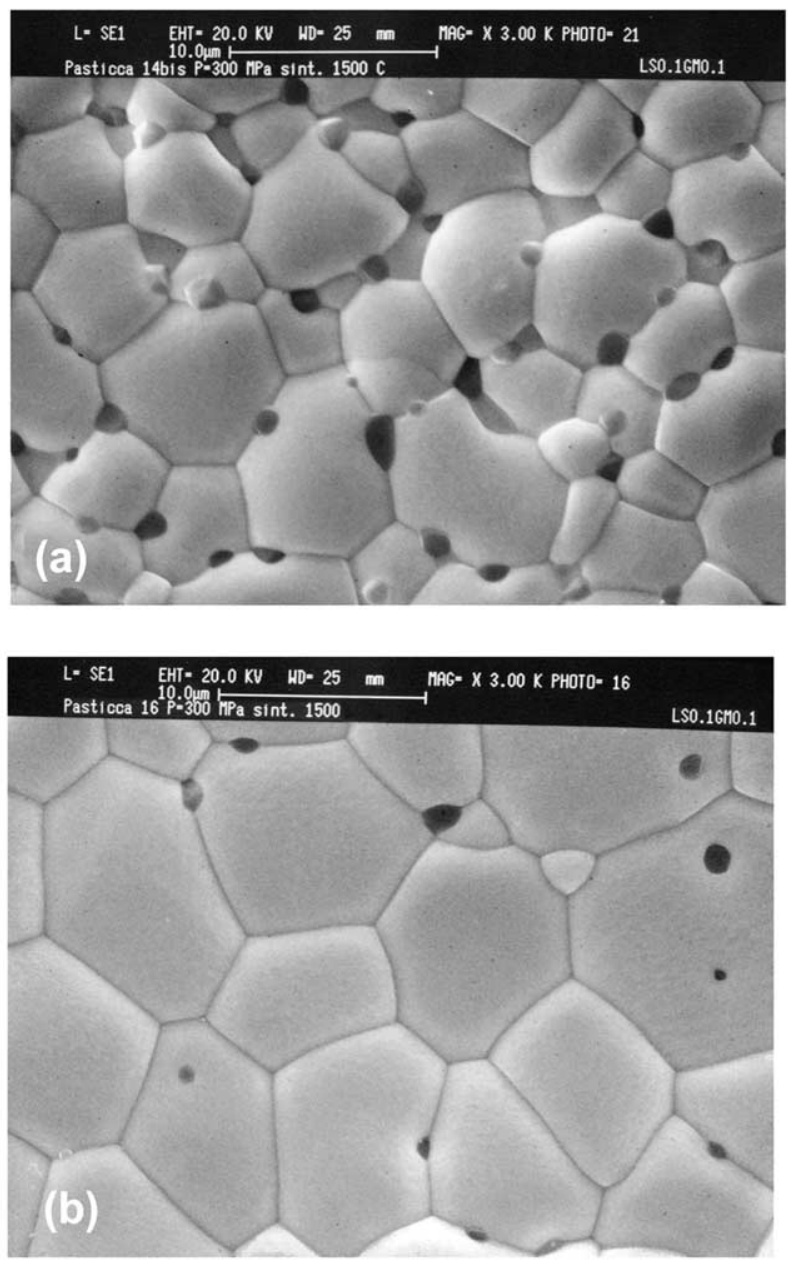

Fig. 5. SEM micrographs of sintered pellets of $\mathrm{LS}_{0.1} \mathrm{GM}_{0.1}$ materials prepared by Pechini (a) or citrate (b) method (powders pressed at 300 $\mathrm{MPa}$ and $10 \mathrm{~h}$ sintered at $1500{ }^{\circ} \mathrm{C}$ ). 
$300 \mathrm{MPa}$ and synthesized by either Pechini or citrate method. The dark features in the SEM micrographs are not pores, but, as confirmed by spot EDS analysis, a $\mathrm{Mg}$-containing phase which we hypothesise to be $\mathrm{MgO}$ even if XRD spectra of sintered samples did not show evident diffraction peaks of $\mathrm{MgO}$ phase. In fact, it's worth recalling here that such small amounts of $\mathrm{MgO}$ cannot be easily detected by XRD due to the low values of the form factors of $\mathrm{Mg}$ and $\mathrm{O}$ atoms. Moreover, $\mathrm{MgO}$ was not observed by SEM-EDS in calcined powders, even in samples containing higher magnesium levels ( $\mathrm{y}>0.1$, see Fig. 3). Therefore, we infer that the formation of $\mu \mathrm{m}$-sized $\mathrm{MgO}$ grains during sintering was consequent to either decomposition of $\mathrm{SrLaGa}_{3} \mathrm{O}_{7}$ or growth of much smaller $\mathrm{MgO}$ clusters, which were already present in the calcined powder prior to sintering, but not visible by SEM.

The results of electrical conductivity measurements of $\mathrm{LS}_{0.1} \mathrm{GM}_{0.1}$ materials prepared by both sol-gel methods and of $\mathrm{LS}_{0.1} \mathrm{GM}_{0.2}$ material prepared by citrate synthesis are reported in Fig. 6 in the form of Arrhenius plot. The data show that conductivity, which is expected to be purely ionic for these materials, ${ }^{13,14}$ depends on the synthetic route. In fact, $\mathrm{LS}_{0.1} \mathrm{GM}_{0.1}$ pellets prepared from powders synthesised by Pechini process exhibited a lower conductivity. Also the activation energy was slightly higher, being 1.42 and $1.32 \mathrm{eV}$ for $\mathrm{LS}_{0.1} \mathrm{GM}_{0.1} / \mathrm{P}$ and $\mathrm{LS}_{0.1} \mathrm{GM}_{0.1} / \mathrm{C}$ materials, respectively. The lower conductivity could be due to the larger amounts of $\mathrm{MgO}$ and of $\mathrm{SrLaGa}_{3} \mathrm{O}_{7}$ phases in $\mathrm{LS}_{0.1} \mathrm{GM}_{0.1} / \mathrm{P}$ pellets (Figs. 4 and 5), which reduced the level of dopants in the perovskite phase and, therefore, the concentration of oxygen vacancies. The activation energy values were found to be larger than those reported in the relevant literature for pure LSGM materials. ${ }^{6,15}$ This suggests that the presence of secondary phases could represent an obstacle to oxygen ion diffusion. $\mathrm{LS}_{0.1} \mathrm{GM}_{0.2} / \mathrm{C}$

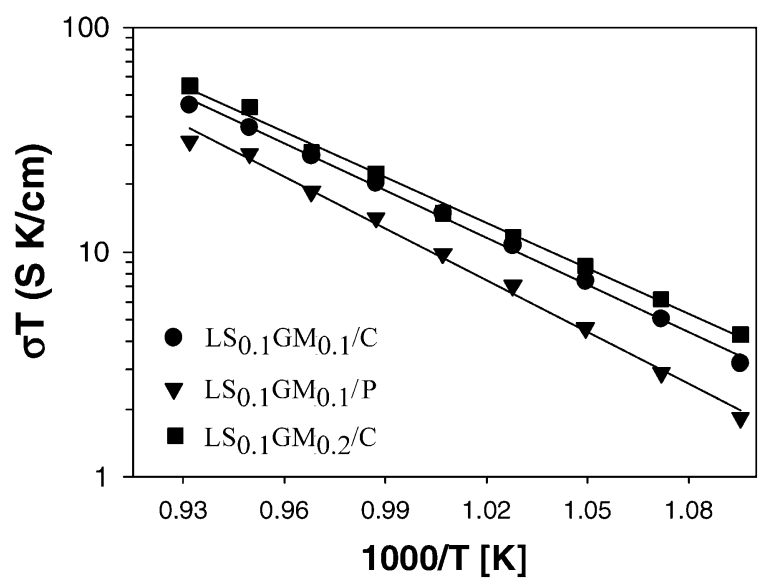

Fig. 6. Arrhenius plots for $\mathrm{La}_{1-x} \mathrm{Sr}_{x} \mathrm{Ga}_{1-y} \mathrm{Mg}_{y} \mathrm{O}_{3-\delta}\left(\mathrm{LS}_{x} \mathrm{GM}_{y}\right)$ pellets sintered $\left(10 \mathrm{~h}\right.$ at $\left.1500{ }^{\circ} \mathrm{C}\right)$ from powders prepared by Pechini $(/ \mathrm{P})$ or citrate (/C) sol-gel method. pellets showed a higher conductivity, as expected for a material having a larger vacancy concentration, and an activation energy $(1.34 \mathrm{eV})$ quite close to that of $\mathrm{LS}_{0.1} \mathrm{GM}_{0.1} / \mathrm{C}$. However, the conductivity value at $800^{\circ}$ $\left(0.051 \mathrm{~S} \mathrm{~cm}^{-1}\right)$ was only slightly larger than that of YSZ $\left(0.046 \mathrm{~S} \mathrm{~cm}^{-1}\right),{ }^{16}$ thus suggesting that phase purity is a critical issue insofar as low temperature conductivity of LSGM materials is concerned.

\section{Conclusions}

$\mathrm{La}_{1-x} \mathrm{Sr}_{x} \mathrm{Ga}_{1-y} \mathrm{Mg}_{y} \mathrm{O}_{3-\delta}\left(\mathrm{LS}_{x} \mathrm{GM}_{y}\right)$ perovskites were prepared with different strontium and magnesium levels by using two sol-gel methods. Pure powders could not be obtained even after $10 \mathrm{~h}$ calcination at $1500{ }^{\circ} \mathrm{C}$. In fact $\mathrm{SrLaGa}_{3} \mathrm{O}_{7}$ phase was detected by XRD in all calcined powders. Citrate method did allow to obtain purer $\mathrm{LS}_{x} \mathrm{GM}_{y}$ powders than Pechini-type process. Moreover, the amount of Sr- and Ga-containing secondary phase was found to depend also on the concentration of dopants, i.e. $x$ and $y$ values. After sintering, the presence of $\mathrm{SrLaGa}_{3} \mathrm{O}_{7}$ was significantly reduced up to levels undetectable by XRD in the case of materials prepared by citrate method, which therefore proved to be a better synthetic route than Pechini process. However, SEM-EDS data showed that $\mathrm{MgO}$ segregation took place during sintering, with deleterious effects on the ionic conductivity of the materials.

\section{References}

1. Ishihara, T., Matsuda, H. and Takita, Y., Doped $\mathrm{LaGaO}_{3}$ perovskite type oxide as a new oxide ionic conductor. $J$. Am. Chem. Soc., 1994, 116, 3801-3803.

2. Huang, P. and Petric, A., Superior oxygen ion conductivity of lanthanum gallate doped with strontium and magnesium. J. Electrochem. Soc., 1996, 143, 1644-1648.

3. Huang, K., Feng, M. and Goodenough, J. B., Sol-gel synthesis of a new oxide-ion conductor Sr- and $\mathrm{Mg}$-doped $\mathrm{LaGaO}_{3}$ perovskite. J. Am. Ceram. Soc., 1996, 79, 1100-1104.

4. Maric, R., Ohara, S., Fukui, T., Yoshida, H., Nishimura, M., Inagaki, T. and Miura, K., Solid oxide fuel cells with doped lanthanum gallate electrolyte and $\mathrm{LaSrCoO}_{3}$ cathode, and Nisamaria-doped ceria cermet anode. J. Electrochem. Soc., 1999, 146, 2006-2010.

5. Djurado, E. and Labeau, M., Second phases in doped lanthanum gallate perovskites. J. Europ. Ceram. Soc., 1998, 18, 1397-1404.

6. Stevenson, J. W., Armstrong, T. R., McCready, D. E., Pederson, L. R. and Weber, W. J., Processing and electrical properties of alkaline earth-doped lanthanum gallate. J. Electrochem. Soc., 1997, 144, 3613-3620.

7. Huang, K. and Goodenough, J. B., Wet chemical synthesis of Srand $\mathrm{Mg}$-doped $\mathrm{LaGaO}_{3}$, a perovskite-type oxide-ion conductor. J. Sol. State Chem., 1998, 136, 274-283.

8. Tas, A. C., Majewski, P. and Aldinger, F., Chemical preparation of pure and strontium- and/or magnesium-doped lanthanum gallate powders. J. Am. Ceram. Soc., 2000, 83, 2954-2960.

9. Majewski, P., Rozumek, M., Tas, C. A. and Aldinger, F., 
Processing of $(\mathrm{La}, \mathrm{Sr})(\mathrm{Ga}, \mathrm{Mg}) \mathrm{O}_{3}$ solid electrolyte. J. Electroceram, 2002, 8, 65-73.

10. Pechini, M., U.S. Patent No. 3330697 (11 July 1967).

11. Ciambelli, P., Cimino, S., Lisi, L., Faticanti, M., Minelli, G., Pettiti, I. and Porta, P., La, $\mathrm{Ca}$ and Fe oxide perovskites: preparation, characterization and catalytic properties for methane combustion. Appl. Catal. B, 2001, 33, 193-203 (and references therein).

12. Majewski, P., Rozumek, M., Tas, C. A. and Aldinger, F., Phase diagram studies in the systems $\mathrm{La}_{2} \mathrm{O}_{3}$ - $\mathrm{SrO}-\mathrm{MgO}-\mathrm{Ga}_{2} \mathrm{O}_{3}$ at 1350 $1400{ }^{\circ} \mathrm{C}$ in air with emphasis on $\mathrm{Sr}$ and $\mathrm{Mg}$ substituted $\mathrm{LaGaO}_{3}$. J. Alloys Comp., 2001, 329, 253-258.

13. Ishihara, T., Matsuda, H., bin Bustam, M. A. and Takita, Y.,
Oxide ion conductivity in doped Ga based perovskite type oxide. Solid State Ionics, 1996, 86-88, 197-201.

14. Kim, J.-H. and Yoo, H.-I., Partial electronic conductivity and electrolytic domain of $\mathrm{La}_{0.9} \mathrm{Sr}_{0.1} \mathrm{Ga}_{0.8} \mathrm{Mg}_{0.2} \mathrm{O}_{3-\delta}$. Solid State Ionics, 2001, 140, 105-113.

15. Huang, K., Tichy, R. S. and Goodenough, J. B., Superior perovskite oxide-ion conductor; strontium- and magnesium-doped $\mathrm{LaGaO}_{3}$ : I, phase relationships and electrical properties. J. Am. Ceram. Soc., 1998, 81, 2565-2575.

16. Drennan, J., Zelizko, V., Hay, D., Ciacchi, F. T., Rajendran, S. and Badwal, S. P. S., Characterisation, conductivity and mechanical properties of the oxygen-ion conductor $\mathrm{La}_{0.9} \mathrm{Sr}_{0.1}$ $\mathrm{Ga}_{0.8} \mathrm{Mg}_{0.2} \mathrm{O}_{3-\mathrm{x}}$. J. Mater. Chem., 1997, 7, 79-83. 